\title{
FINE PARTICLE CLAY CATALYSTS FOR COAL LIQUEFACTION
}

\author{
Quarterly Technical Report for the Period \\ May 9, 1991, through August 8, 1991
}

\author{
by \\ Edwin S. 01 son, Principal Investigator \\ Universal Fuel Development Associates, Inc. \\ 223 Circle Hills Drive \\ Grand Forks ND 58201 \\ Prepared for: \\ United States Department of Ener'yy \\ Under Contract Number DE-AC22-91PC90048
}

\section{DISCLAIMER}

This report was prepared as an account of work sponsored by an agency of the United Str 'es Government. Neither the United States Government nor any agency thereof, nor any of their employees, makes any warranty, express or implied, or assumes any legal liability or responsibility for the accuracy, completeness, or usefulness of any information, apparatus, product, or process "isclosed, or represents that its use wouid not infringe privately owried rights. Reference herein to any specific commercial product, process, or service by trade name, trademark, manufacturer, or otherwise does not necessarily constitute or imply its endorsement, recommendation, or favoring by the United States Government or any agency thereof. The views and opinions of authors expressed herein do not necessarily state or reflect those of the United States Government or any agency thereof. 


\section{TABLE OF CONTENTS}

Page

EXECUTIVE SUMMARY

2.0 GOALS AND OBJECTIVES

3.0 ACCOMPLISHMENTS

3.1 Introduction

3.2 Experimental

3.3 Results and Discussion

3.3.1 Preparation of Iron-Pillared Clays

8

3.3.2 Characterization of Iron-Pillared Clays

11

4.0 REFERENCES 


\subsection{EXECUTIVE SUMMARY}

The investigation of methods for the production and testing of ironpillared clay catalysts was continued in this quarter. Answers were obtained to several questions that were raised as a result of work in the first quarter. The first of these concerned the difference in composition and catalytic activity of catalysts prepared from the fine and larger particles of the iron-intercalated clay. Previously the fine particles had considerable hematite content, and the sulfided catalyst prepared from the fine particles had a much lower activity in hydrocracking tests. A new method was used for preparation of the fine particles of triiron acetate-intercalated montmorillonite. The exchanged clays were collected as rapidly as possible and calcined to generate iron-pillared montmorillonites. In this case, X-ray diffraction showed that the calcined catalyst from the fine particle had a much smaller amount of hematite than the catalyst prepared using the earlier method. Thus the composition of catalysts from fine and large particles consisted mostly of maghemite on the clay support. The hydrocracking activities of both the sulfided and nonsulfided iron-pillared clay catalysts prepared from the fines and larger particles were the same.

A second question was concerned with the concentration of iron introduced into the clay. Use of a smaller amount of iron might result in a lower number of pillars and consequently result in a larger micropore volume. Exchange of one-third of the total equivalents of sodium by the triiron acetate cation rather than using an excess of the triiron gave a catalyst after calcination and sulfidation that was as active in hydrocracking reactions as the catalyst prepared with excess triiron complex (large particle fraction). The fine particle fraction had a lower activity.

The presence of excess sodium in the catalyst brings up another question regarding the possible loss of Bronsted acidic sites due to presence of the sodium salt. The sodium ions were exchanged out of one of the clays with ammonium ions following the iron-exchange. Calcination of this precursor gave a very active catalyst, because of thermal loss of ammonia and generation of the Bronsted acid sites.

A comparison of the sulfided versus nonsulfided forms of the iron-pillared clays showed that the nonsulfided forms had a much lower hydrocracking activity. The effect of sulfidation on the acidity of the support is probably not significant. Although the iron sulfide does not activate hydrogen well enough for addition to single aromatic rings (benzene to cyclohexane), it must be able to activate hydrogen for addition to some intermediates that can in turn serve as effective hydride donors for reduction of carbonium ions in the hydrocracking cleavage reactions. Thus the synergistic effect of hydrogen activator and support acidity is we 11 demonstrated by this experiment. Retrograde condensation reactions and coking did not occur with these catalysts.

In addition to effective catalys is of hydrocracking reactions at moderate temperatures, the iron-pillared clays were superior catalysts for catalyzing the hydrogenation of pyrene. Hydrocracking of the hydrogenated pyrenes was not observed at low temperatures, and hydrocracking reactions have not yet been studied at higher temperatures with these catalysts. 
PETC is developing coal 1 iquefaction methods utilizing dispersed molybdenum and iron catalysts formed by addition of the metal cations to coal, followed by chemical or thermal activation. Dispersed iron sulfides could also be easily prepared by addition of solutions of ferric salts to clays followed by treatment with ammonia and/or sulfidation. The resulting catalyst was, however, very unreactive. These conditions did not give pillared clays, and also did not generate significant amounts of acidic sites. Although this method may give iron sulfides with some activity for hydrogen addition to polynuclear aromatics, it does not generate the activation catalyst-acidic support interaction needed for effective hydrocracking. In the effort to improve this method in third quarter, we are investigating the addition of ferric nitrate and other iron complexes to acid-pretreated clays.

A general problem with the iron-pillared clays is that the calcination and/or sulfidation treatments appear to mobilize the iron and generate particles of the iron oxide and sulfide that are larger than desired for maximum utilization of the iron. Surface areas are also substantially decreased, owing to collapse of the layer structure. In the third quarter we are using much lower concentrations of iron with clays and alumina-pillared clays (discrete mixed pillared clays) and new methods of pillaring that may give a more effective particle size for the iron sites and more stable pillared structures.

\subsection{GOALS AND OBJECTIVES}

The efficient production of environmentally acceptable distillate fuels requires catalysts for hydrogenation and cleavage of the coal macromolecules and removal of oxygen, nitrogen, and sulfur heteroatoms. The goal of the proposed research is to develop new catalysts for the direct liquefaction of coal. This type of catalyst consists of fine clay particles that have been treated with reagents which form pillaring structures between the aluminosilicate layers of the clay. The pillars not only hold the layers apart but also constitute the active catalytic sites for hydrogenation of the coal and the solvent used in the liquefaction. The pillaring catalytic sites are composed of pyrrhotite, which has been previously demonstrated to be active for coal liquefaction. The pyrrhotite sites are generated in situ by sulfiding the corresponding oxyiron species. The size of the catalyst will be less than $40 \mathrm{~nm}$ in order to promote intimate contact with the coal material. Since the clays and reagents for pillaring and activating the clays are inexpensive, the catalysts can be discarded after use, rather than regenerated by a costly process.

The proposed work will evaluate methods for preparing the fine particle iron-pillared clay dispersions and for activating the particles to generate the catalysts. Characterization studies of the pillared clays and activated catalysts will be performed. The effectiveness of the pillared clay dispersion for hydrogenation and coal liquefaction will be determined in several types of testing. 


\subsection{ACCOMPLISHMENTS}

\subsection{Introduction}

The development and testing of disposable fine particle heterogeneous catalysts for hydrotreating of coals was continued. These catalysts corsist of sulfided iron clusters intercalated into smectite clays. The smectite clays are swelling phyllosilicate minerals, commonly found as components of soils and iediments and often found as large, mineralogically pure deposits (1). These materials are highly useful in many chemical applications, because of their small particle size (<2 micrometers) and appreciable surface area for the adsorption of organic molecules and unique intercalating capabilities. Hence they are used for supporting microcrystalline or metal cluster catalytic sites. Acid-modified smectites were used for a number of years as petroleum cracking catalysts in the Houdry process, giving gasoline in high yields (1). In the mid 1960's they were replaced by more thermally stable and selective zeolite catalysts.

The advantages of two dimensional chemistry in the interlayer space of the clay structure have recently been investigated. One of the major themes is the intercalation of metal complex catalysts between the aluminosilicate layers. An improvement in catalytic specificity relative to homogeneous solution can be achieved by mediating the chemical and physical forces acting on interlayer reactants. The use of large stable cations to pillar the aluminosilicate layers results in the formation of porous networks analogous to zeolites. In these pillared clays, intercalation of hydroxylated or complexed metal cations maintains the clay layer structure after loss of water and generates a large micropore dimension. These structures are stable up to 450 to $500^{\circ} \mathrm{C}$ in contrast to the nonpillared clays which dehydrate and collapse at temperatures over $200^{\circ} \mathrm{C}$. Acid zeolites are more stable at high temperatures; however, their pores are too narrow to be useful for coal macromolecules. The advantage of the pillared clay catalyst over the zeolites is that pore size can be controlled and made larger than those of the zeolites, and hence are more suitable for the adsorption of the coal macromolecules. Therefore, these pillared clay catalysts may be more effective in cracking coal macromolecules than the conventional catalysts. The intent of this work is to discover how to finely disperse the iron sulfide catalytic sites in the pillared clay structure.

Work in the second quarter continued the study of preparation methods for iron-pillared montmorillonites. The sodium form of this clay disperses to an extremely fine particle size in an aqueous medium with low concentrations of base. This form is preferred for the metal ion exchange reaction that gives the intercalated clay, since the clay layers are highly separated in this state and mass transfer is rapid. At this point the iron metal is highly dispersed as intercalated polyoxymetal cations. The iron-exchanged clay was subsequently calcined to form the iron oxide pillars. We expected at this point that the iron would still be highly dispersed as pillars. It is likely, however, that calcining affected not only the size of the clay particles, but also the particle size of the iron clusters within the clay layers. The forms of iron present after intercalation, calcining and sulfidation need to be better understood. The relationship between preparation methods, starting materials (clay type and iron type), initial particle sizes, and resulting catalytic activities will be determined in subsequent studies. 


\subsection{Experimental}

\subsubsection{Catalyst Preparation}

Iron-pillared clay catalysts were prepared as follows:

\subsubsection{Purification of Smectite Clay}

Na-montmorillonite from Clay Spur, Wyoming, USA, was purified as described in our previous quarterly report (2).

\subsubsection{Preparation of pillaring reagent}

Trinuclear acetato-hydroxo iron(III) nitrate, $\left[\mathrm{Fe}_{3}\left(\mathrm{OCOCH}_{3}\right), \mathrm{OH} .2 \mathrm{H}_{2} \mathrm{O}\right] \mathrm{NO}_{3}$ was prepared according to the method reported by Yamanaka et al. (3). Detailed procedure has been described in the previous quarterly report (2).

\subsubsection{Exchange/Pillaring Reactions}

High triiron acetate concentration

Na-montmorillonite was exchanged with a solution containing a large excess of trinuclear acetato-hydroxo iron(III) nitrate in the manner described in the previous quarterly report, but the isolation of the intercalated clay was changed to give a more rapid collection of the fine particles. The exchanged clay was centrifuged at $3000 \mathrm{rpm}$ speed for 15 minutes to separate larger particles. The collected large particles were washed with water several times, dried in vacuo at $50^{\circ} \mathrm{C}$, and calcined at $350^{\circ} \mathrm{C}$ for 6 hours to give the large particle excess iron pillared clay (LEIPC). The supernatant liquid was quickly centrifuged at 15000 rpm speed. The residue of fine particle intercalated clay was washed with water several times, dried in vacuo at $50^{\circ} \mathrm{C}$, and calcined at $350^{\circ} \mathrm{C}$ for 6 hours to give the fine particle excess iron pillared clay (FEIPC). Both iron-pillared clays were ground to -200 mesh.

Low trifron acetate concentration

Na-montmorillonite was also exchanged with $1 / 3$ of the equivalents of triiron complex required for complete exchange ( $80 / 3$ milliequivalents $/ 100 \mathrm{~g})$. All the triiron complex was taken up by the clay. The resulting product was centrifuged at $3000 \mathrm{rpm}$. The residue was washed with water several times, and dried by evacuation at $50^{\circ} \mathrm{C}(30 \%$ yield). This iron-intercalated clay was calcined at $350^{\circ} \mathrm{C}$ for 6 hours, and ground to -200 mesh. The resulting product was brown in color and will be referred as L.3IPC (1arge particle iron-pillared clay). The filtrate and washings were divided into two parts. One part was centrifuged at $15000 \mathrm{rpm}$ and washed with water several times, and dried by evacuation at $50^{\circ} \mathrm{C}$, and calcined at $350^{\circ} \mathrm{C}$. The resulting product was brown as before and will be referred as F.3IPC (fine particle iron-pillared clay). 
Low sodium concentration

To the second portion of the fines, $50 \mathrm{ml}$ of $0.1 \mathrm{M}$ ammonium nitrate was added and stirred for 30 minutes. The resulting slurry was centrifuged at $15000 \mathrm{rpm}$. The residue was washed with water several times, dried in vacuo at $50^{\circ} \mathrm{C}$, and calcined at $350^{\circ} \mathrm{C}$ for 6 hours. The ammonium nitrate-exchanged fine particle iron-pillared clay (AF.3IPC) was ground to -200 mesh.

Ferric ion exchanged clay

Iron hydroxy oxide was supported on Na-montmorillonite according to the method of Cugini and co-workers (4). A suspension of $2 \mathrm{~g}$ of sodium montmorillonite in $200 \mathrm{ml}$ deionized water was placed in a $500 \mathrm{ml}$ two necked round bottomed flask. To this suspension, a solution of $0.4 \mathrm{~g}$ of iron(III) nitrate nonahydrate dissolved in $16 \mathrm{ml}$ water was added with vigorous stirring. To the above slurry, a solution of $8 \mathrm{~g}$ of ammonium hydroxide (29\% ammonia) dissolved in $80 \mathrm{ml}$ deionized water, and stirred for 30 minutes. The solid was separated by high speed $(15,000 \mathrm{rpm})$ centrifugation. The residue was washed with deionized water several times, dried in vacuo at $50^{\circ} \mathrm{C}$, and calcined in air at $350^{\circ} \mathrm{C}$ for 6 hours. The solid ground to -200 is referred to as SMFeOOH. The catalyst was sulfided at 275 and $400^{\circ} \mathrm{C}$ for 2 hours in 1000 psig of $\mathrm{H}_{2} \mathrm{~S}$ and $\mathrm{H}_{2}\left(10 \% \mathrm{H}_{2} \mathrm{~S}\right)$.

\subsubsection{Sulfidation of Triiron Acetate-Intercalated Clays}

The desired catalyst was placed in a $10 \mathrm{ml}$. microreactor or $70 \mathrm{ml}$ Parr reactor. The reactor was evacuated, pressurized with 100 psi of $\mathrm{H}_{2} \mathrm{~S}$ and 900 psi of $\mathrm{H}_{2}$, and placed in a rocking heater preheated to $400^{\circ} \mathrm{C}$. The heating was continued for 2 hours. The reactor was then cooled to room temperature, degassed, and the sulfided catalyst was stored in air tight ampules.

\subsubsection{Analytical procedures and Instrumentation}

Quantitative GC/FID analyses were performed with a Hewlett Packard $5880 \mathrm{~A}$ gas chromatograph equipped a Petrocol capillary column. A mixture of 2,2,4trimethylpentane and n-octadecane was the internal standard. GC/FTIR/MS was performed on a Finnigan 800 ITD ion trap detector with a HP 5890A gas chromatograph and a J\&W 30-m $\times 0.32-\mathrm{mm}$ (ID), 1.0-micron film of DB-5.

For X-ray powder diffraction (XRD) analysis, the pillared clay is ground with water and smeared onto a single crystal, "zero"-background, quartz plate to obtain an oriented specimen so as to give intense 001 basal reflections. Diffraction data are collected in $0.02^{\circ}$ steps for one second dwell time using a Philips automated diffractometer equipped with a copper tube, theta-compensating slit, graphite diffracted beam monochromator, and scintillation detector. Software programs supplied by Materials Data Incorporated are used for data collection, data reduction, and phase identification.

Total sulfur analysis was done with a LECO model 532 sulfur analyzer using the ASTM D1551 method. Iron, silicon, and aluminum were analyzed by $A A$ spectroscopy. 
Surface area measurements were performed with a Micromeritics AccuSorb $2100 \mathrm{E}$ static unit for nitrogen physisorption at $77 \mathrm{~K}$ (BET method).

Particle size analysis was performed with Malvern Instruments Particle Sizer model M6.10. The clay samples were dispersed in ethanol as well as water, and particle size distributions were determined using 63-300 mm Lens Sma11 Cel1 at several time intervals.

\section{2 .3 Catalytic hydrotreating}

In a typical run, $0.50 \mathrm{~g}$ of the test compound and $0.25 \mathrm{~g}$ of the desired catalyst were placed in a microreactor (tubing bomb). The microreator was evacuated and pressurized with $1000 \mathrm{psi}$ of hydrogen, and placed in a rocking autoclave heated to $350^{\circ} \mathrm{C}$ for 3 hours. At the end of the reaction period, The microreactor was cooled to room temperature, degassed, and opened. The desired amount of the internal standard was added to the product slurry, and the product slurry was transferred into a centrifugation tube by washing with methylene chloride, and solid catalyst removed by centrifugation. The liquid sample was. analyzed by GC-FID and GC/FTIR/MS. The solid was dried in vacuum at $110^{\circ} \mathrm{C}$ for 3 hours.

\subsection{Results and Discussion}

\subsubsection{Preparation of Iron-Pillared Clays}

\subsubsection{High triiron acetate concentration}

The sodium form of montmorillonite exists in a very finely dispersed state in a low ionic strength neutral aqueous medium. The aluminosilicate layers of the clay are believed to be separated to the extent that ion exchange of associated cations is relatively unhindered. Iron was introduced as the trifron acetato complex monoanion (3). Earlier work with ferric salts gave clays in which the iron was not intercalated but was associated with outer layers (5). In the previous quarter, the fine particles of iron-intercalated clay were collected from the supernatant and washings after isolation of the larger particles. The calcined fine particles contained a substantial amount of hematite, which was attributed to hydrolysis of the triacetate that occurred over several days exposure to the aqueous solutions. The preparative work in the second quarter avoided this delay by shortening the initial centrifugation time and immediately centrifuging the supernatant in the high speed centrifuge. The calcined large and fine particles pillared clays obtained in this modified procedure were given the terms LEIPC and FEIPC.

\subsubsection{Low triiron acetate concentration}

The relatively narrow line widths observed in previous XRD studies indicated that the particle size of the maghemite and hematite present in the calcinad clays may be fairly large and consequently could disrupt the clay layer structure and result in low dispersion of the iron in the catalyst and low micropore dimensions. By exchanging a relatively small amount of iron into the clay, it was hoped that fewer pillars would be created and the iron oxide 
particles would be smaller. Exchange of only $1 / 3$ of the total equivalents of sodium by iron resulted in a $30 \%$ yield of larger iron-intercalated particulates and $70 \%$ yield of fine particles. Calcination gave the iron-pillared clays (L.3IPC and F.3IPC) which contained lower amounts of iron.

\subsubsection{Low sodium concentration}

Since the partially exchanged clays contained substantial amounts of sodium ions that could mask the acid catalytic sites, part of the fine particles from the preparation described above were treated with ammonium nitrate to replace the sodium ions. Iron was not removed in this treatment. Calcination removed the ammonium as ammonia along with water to give the iron-pillared clay with low sodium content (AF.3IPC).

\subsubsection{Ferric iron exchange}

Since active iron sulfide catalysts can be rearily prepared by addition of ferric nitrate to coal, followed by treatment with ammonium hydroxide (4), it was of great interest to see whether this expedient method could be used to prepare a dispersed iron sulfide by addition of ferric ion to clay (sodium or calcium montmorillonite) and subsequent treatment with ammonia. The method was tried with sodium montmorillonite.

\subsubsection{Characterization of Iron-Pillared Clays}

\subsubsection{XRD Analysis}

Iron-pillared montmorillonite catalysts were characterized by elemental, particle size, surface area, and X-ray diffraction (XRD) analyses. Since pillared clays usually show only broad XRD patterns, the use of oriented specimens is helpful for measuring the basal spacing unambiguously. In addition to preferred orientation, XRD analysis using random orientation was also performed.

Figure 1 shows the XRD $2 \theta$ plots obtained for the iron-pillared clays resulting from calcination of the large (Fig.1A) as well as fine (Fig.1B) particle iron-intercalated montmorillonites. Both samples exhibited major lines corresponding to maghemite $\left(2 \theta=36^{\circ}\right)$. Hematite $\left(2 \theta=33^{\circ}\right)$ was nresent as a minor component in both FEIPC and LEIPC. The FEIPC contained sul,lewhat more hematite than the LEIPC, but much less than that obtained previously for the FPIPC. The FPIPC catalyst prepared by a more lengthy procedure in the previous quarter contained significant amounts of hematite, which may have been formed from the hydrolysis of intercalated triiron complex due to prolonged contact of the intercalated clay with pillaring solution. Thus speedy collection of the iron-intercalated fine particles mostly prevented the formation of hematite in the calcined product. The more rapid isolation of particles from the aqueous solution may represent a significant improvement in the preparation, because the hematite formation observed earlier was associated with much lower activity of the catalyst. The reasons for the decrease in activity are not yet understood, however. 
XRD analysis of the sulfided FEIPC and LEIPC, which had been heated in 200 psi of hydrogen sulfide at $350^{\circ} \mathrm{C}$ for 2 hours, indicated the complete conversion of iron oxide to pyrite. Elemental analyses confirmed this fact: S/Fe ratios of the sulfided FEIPC and LEIPC were 1.85 and 1.96 respectively indicating the conversion of triiron into mainly pyrite. Since pyrite was not the desired iron form, the sulfided catalysts were reheated in $1000 \mathrm{ps} i$ of hydrogen at $350^{\circ} \mathrm{C}$ for 2 hours, and analyzed by XRD. The XRD data indicated that pyrrhotite was the only crystalline phase present in this sample.

When sulfidation of the calcined materials was carried out at $400^{\circ} \mathrm{C}$ for 2 hours in the presence of a 1000 pst mixture of hydrogen sulfide and hydrogen ( $10 \%$ $\left.\mathrm{H}_{2} \mathrm{~S}\right)$, conversion of intercalated tritron to pyrrhotite was complete. Narrow lines for pyrrhotite were observed in the XRD plot (Figure 2). The particle size and the distribution of pyrrhotite in the clay interlayer structure could not be ascertained from these data. The $d_{001}$ peak corresponding to the interlayer spacing was quite broad in the $2 \theta$ plot for both samples. This may indicate that the spacings are irregular in the calcined products.

The observance of relatively narrow lines for the maghemite in the calcined clay and pyrrhotite and pyrite in the sulfided clays may indicate that the particle size of the iron in the clay may be larger than desired for high catalyst activity. Thus calcining may mobilize the iron so that not only iron pillars, but also larger iron oxide particles are present (6), and the latter can disrupt the layer structure sufficiently so that lower micropore volumes exist in the structure. There may be several ways to overcome this problem, including use of mixed alumina/iron pillars and new methods of creating the pillars via organic pillar replacement. These methods are under investigation in the third quarter.

In the case of the catalyst prepared by adding ferric ion to sodium montmorillonite, followed by ammonia treatment and sulfidation, XRD data indicated the complete conversion of iron hydroxy oxide to pyrrhotite. But these data did not provide any information regarding the particle size of the iron sites obtained by sulfiding at the two different temperatures. The $2 \theta$ plot has lines consistent with those of sodium montmorillonite. Thus it is not likely that iron was intercalated into the clay structure or formed any pillars in this material.

\subsubsection{Particle Size Analys is}

In order to determine the effect of intercalation of iron oxide into the clay interlayer structure on the particle size distribution, the particle size distribution of the starting clay was also determined. Na-montmorilionite was suspended in enough water to obtain a $1 \%$ clay suspension. The particle size distribution was determined using $63 \mathrm{~mm}$ Lens small cell in ethanol and water. In water, the particle size ranged from 6 micron to less than 1 micron. With time the particles became larger, and after 30 minutes of standing the clay particles ranged from 11 micron to less than 1 micron. The yield of the particles less than 1 micron was $23 \%$. The average particle size of the clay was much smaller in water than in ethanol. Particle size determined in ethanol ranged from 120 to less than 1 microns. The yield of the particles less than 1 
micron was $6 \%$. On standing, the particles continued to grow larger, as with the aqueous suspension.

Intercalation of $\mathrm{Na-montmorillonite} \mathrm{with} \mathrm{the} \mathrm{large} \mathrm{excess} \mathrm{of} \mathrm{tritiron}$ complex resulted in a significant increase in the particle size of the intercalated clay. The particle size of the FEIPC varied from 108 to 3.4 microns in water. Particle size was found to increase upon isolation and calcination. Once calcined, the intercalated clay did not disperse in water or ethanol. Particle size increased significantly upon sulfidation of the clay intercalated with large excess of trition complex (FEIPC).

Intercalation of $\mathrm{Na-montmorill}$ onite with 0.33 equivalent of triiron complex (F.3IPC) gave larger particles than those obtained with the large excess of triiron complex (FEIPC). As before the particles continued to grow larger upon standing.

\subsubsection{Surface Area Analys is}

Surface areas of the fine particle (FEIPC) and large (LEIPC) particle ironpillared clay catalysts were 156 and $181 \mathrm{~m}^{2} / \mathrm{g}$ respectively. However, on sulfiding the fine particle iron-pillared clay (FEIPC) catalyst in $\mathrm{H}_{2} \mathrm{~S}$ and $\mathrm{H}_{2}$ at $400^{\circ} \mathrm{C}$ for 2 hours the surface area dropped to $17 \mathrm{~m}^{2} / \mathrm{g}$. The reduction in surface indicates the collapse of the interlayer structure or formation of iron sulfide agglomerates.

Further characterization of the iron-pillared clays by acidity studies, IR, TGA, and Mossbauer spectroscopy is in progress and wi11 be reported in our next quarterly.

\subsubsection{Testing of Iron-Pillared Montmorillonite Catalysts}

\subsubsection{Catalytic Hydrocracking of Bibenzyl}

Hydrocracking activities of iron-pillared clay catalysts were tested by reacting with tibenzyl as the test compound. Reactions were carried out $350^{\circ} \mathrm{C}$ for 3 hours in the presence of $1000 \mathrm{psi}$ of molecular hydrogen in a $10 \mathrm{ml}$ rocking autoclave reactor. Conversion data and major products are presented in Table 1 . The catalysts were recovered in almost quantitative amounts, and no retrograde reactions or coke were observed during reactions.

The catalytic activities of the precursor iron oxide forms (nonsulfided forms) of the fine particle- (FEIPC) and large particle (LEIPC) iron-pillared clay catalysts were tested with bibenzyi as the substrate in order to separately determine the effects of the iron sulfide and the supporting clay structure. It was expected that the main activity of the iron sulfide sites would be to activate hydrogen, whereas the pillared clay would contain the acidic sites responsible for the cracking mechanism. Rolatively weak hydrocracking activity was observed for the nonsulfided FEIPC and LEIPC (36 and $40 \%$ conversions respectively). These values are consistent with those obtained for other clay supports. The similarity in the conversions of the pillared clays obtained from the large and fine particle iron-intercalated precursors indicates that when 
TABLE 1

CATALYTIC HYDROTREATING OF BIBENZYL

Reaction Time $=3 \mathrm{hrs}$, Reaction Temp. $=350^{\circ} \mathrm{C}, \mathrm{H}_{2}=1000 \mathrm{psig}$ Catalyst wt./Substrate wt. $=0.5$

\begin{tabular}{|c|c|c|c|}
\hline $\begin{array}{l}\text { Catalyst } \\
(\mathrm{g})\end{array}$ & $\begin{array}{l}\text { Substrate } \\
\text { (mmol) }\end{array}$ & $\begin{array}{l}\text { Conversion } \\
(\%)\end{array}$ & $\begin{array}{l}\text { Major Products } \\
(\mathrm{mmol})\end{array}$ \\
\hline LEIPC & 2.74 & 40 & $\begin{array}{l}\text { Benzene }(0.78) \\
\text { Toluene }(0.10) \\
\text { Ethylbenzene }(0.13)\end{array}$ \\
\hline $\begin{array}{l}\text { LEIPC } \\
\text { Pre-SuTf. }\end{array}$ & 2.73 & 80 & $\begin{array}{l}\text { Benzene }(1.65) \\
\text { Methylcyclohexane }(0.10) \\
\text { Toluene }(0.15) \\
\text { Ethylbenzene }(0.62) \\
\text { Ethylcyclohexane }(0.02) \\
\text { Indan }(0.06) \\
\text { Tetral in }(0.16)\end{array}$ \\
\hline FEIPC & 2.73 & 36 & $\begin{array}{l}\text { Benzene }(0.62) \\
\text { Toluene }(0.06) \\
\text { Ethylbenzend }(0.08)\end{array}$ \\
\hline $\begin{array}{l}\text { FEIPC } \\
\text { Pre-sulfd }\end{array}$ & 2.77 & 79 & $\begin{array}{l}\text { Benzene }(1.70) \\
\text { Methylcyclohexane (0.05) } \\
\text { Toluene }(0.16) \\
\text { Ethylbenzene }(0.51) \\
\text { Ethylcyclohexane }(0.01) \\
\text { Indan }(0.04) \\
\text { Tetralin }(0.12)\end{array}$ \\
\hline $\begin{array}{l}\text { F.3IPC } \\
\text { Pre-sulfd }\end{array}$ & 2.83 & 33 & $\begin{array}{l}\text { Benzene }(0.52) \\
\text { Toluene }(0.04) \\
\text { Ethylbenzene }(0.07)\end{array}$ \\
\hline $\begin{array}{l}\text { AF.3IPC } \\
\text { Pre-sulfd }\end{array}$ & 2.83 & 64 & $\begin{array}{l}\text { Benzene }(1.25) \\
\text { Toluene }(0.06) \\
\text { Ethylbenzene }(0.20) \\
\text { Methylcyclohexane }(0.01)\end{array}$ \\
\hline $\begin{array}{l}\text { L.3IPC } \\
\text { Pre-sulfd }\end{array}$ & 2.91 & 79 & $\begin{array}{l}\text { Benzene }(1.66) \\
\text { Methylcyclohexane (0.02) } \\
\text { Toluene }(0.12) \\
\text { Ethylbenzene }(0.38) \\
\text { Indan }(0.03) \\
\text { Tetral in }(0.05)\end{array}$ \\
\hline
\end{tabular}


particle collection is done rapidly, there is little difierence in the activity. The lack of a difference in the reactivity of the two nonsulfided clays may be explained by the close similarites in the composition of the iron-intercalated clay structures (low hematite content) as determined by XRD (see discussion above). The main point is that the particle size of the precursor ironintercalated clay was not an important factor in determining activity. More than surface area is involved.

Examination of the products obtained from the reactions of bibenzyl with non-sulfided iron-pillared clays confirmed the significant hydrocracking activity for both of these catalysts. The major products were benzene, toluene and ethyl benzene. Benzene and ethylbenzene were the largest products, and the amount of benzene was considerably more than ethylbenzene. The ratio of benzene to ethylbenzene was 6-8, indicating the further cracking of the ethylbenzene to benzene. These products are indicative of the Bronsted acid catalysis mechanisin. The mechanism involves the ipso protonation of an aromatic ring of bibenzyl, followed by aryl-methylene bond cleavage to form benzene and phenylethyl carbonium ion. The phenylethyl carbonium ion is reduced to ethylbenzene by hydride transier or hydrogenation or could undergo a variety of reactions to give products. This reaction mechanism is common in reactions catalyzed by clays and clay-supported catalysts. The formation of toluene probably occurs via a Lewis acid catalyzed mechanism, since the temperature is too low for homolytic cleavage of the central bond in bibenzyl. Reduction of carbonium ion intermediates in the reaction may or may not involve the iron sites.

The products included many hundreds of other components, indicative of rearrangements and hydrogen addition as well as hydrocracking. The minor components formed as a result of hydrocracking were propylbenzene, butylbenzene, tetral in, ethylbibenzyl, and phenylethylbibenzyl, etc. The alkylbenzene products resulted from hydrogenation of bibenzyl followed by cracking reactions, probably involving Lewis acid sites. Some of the reaction products were addition products of bibenzyl that may be regarded as Friedel Crafts addition products. However, extensive condensation and coke formation were not observed in the reaction. In comparison, the acidic clay catalysts gave larger amounts of condensation products. These results indicate that iron-pillared clays are effective in cleaving aryl-methylene and other $\mathrm{C}-\mathrm{C}$ bonos at lower $\left(350^{\circ} \mathrm{C}\right)$ temperature.

The catalytic activities of the sulfided iron-pillared clays were determined with bibenzyl as the substrate. The iron-pillared clays were sulfided by heating with a $10 \%$ mixture of hydrogen sulfide in hydrogen. With sulfided FEIPC and LEIPC catalysts the conversion of bibenzyl doubled. Major products were same as those obtained with nonsulfided catalysts. However, small amounts of cycloalkanes were also formed. The ratio of benzene/ethylbenzene was considerable smaller (2.7-3.3). These data are almost exactly the same as those obtained in the previous quarter with the large particle catalyst LPIPC.

It is likely that the iron sulfide (pyrrhotite) sites activated hydrogen for transfer to the aromatics or complexed aromatics. Part of the single-ring aromatics were hydrogenated to give cycloalkanes in the reactions with presulfided catalysts. However, a substantial amount of methylcyclohexane was formed, probably from cleavage of the tertiary carbonium ion derived from 
phenylethylcyclohexane or hydrogenation of the ring-protonated bibenzyl. The two catalysts were identical in the proportion of ring-hydrogenated components found in the reaction products.

The effect of the amount of triiron intercalated into the clay on the hydrocracking activity of iron-pillared clay catalysts was also investigated. The reactions were conducted with L.3IPC and F.3IPC, the iron-pillared montmorillonite catalysts prepared with ? imited amounts of iron catalysts. These catalysts were pre-sulfided by heating with a mixture of 1000 psig $\mathrm{H}_{2} \mathrm{~S}$ and $\mathrm{H}_{2}$ $\left(10 \% \mathrm{H}_{2} \mathrm{~S}\right)$ for 2 hours at $400^{\circ} \mathrm{C}$, and reactions with bibenzyl were carried out at $350^{\circ} \mathrm{C}$ for 3 hours in the presence of $1000 \mathrm{psi}$ of hydrogen. The L.3IPC catalyst gave conversion and product distribution similar to LEIPC. However, F.3IPC gave much lower conversion (33\%). The lower activity may be due to hydrolys is of intercalated triiron during work-up, leading to the formation of hematite.

Another factor that may be important in determining the hydrocracking activity of the catalysts is the presence of a residual of sodium ions that could block the acidic sites. One of the iron-exchanged clays (F.3IPC) was treated with $0.1 \mathrm{M}$ ammonium nitrate prior to calcining in order to exchange residual $\mathrm{Na}^{+}$ ions with $\mathrm{NH}_{4}{ }^{*}$ ions. The ammonium-exchanged product was calcined at $350^{\circ} \mathrm{C}$ for 6 hours, and sulfided by heating at $400^{\circ} \mathrm{C}$ for 2 hours in $1000 \mathrm{psig}$ of $\mathrm{H}_{2} \mathrm{~S}$ and $\mathrm{H}_{2}$ $\left(10 \% \mathrm{H}_{2} \mathrm{~S}\right)$. The reaction of sulfided AF.3IPC with bibenzyl gave $64 \%$ conversion. Major products were benzene, toluene, and ethylbenzene. The increase in activity is attributed to the formation of additional Bronsted acid sites from the decomposition of ammonium ions on calcination.

Since coal liquefaction can be carried out with a catalyst generated by adding ferric nitrate to coal and subsequently hydrolyzing to an iron hydroxyoxide form (4), a convenient method for generating an active catalyst may be the addition of ferric nitrate and subsequently ammonia to a clay and then mixing into the coal liquefaction slurry. Reactions were carried out with iron hydroxy oxide supported on Na-montmorillonite and sulfided by heating with a 1000 psig mixture of $\mathrm{H}_{2} \mathrm{~S}$ and $\mathrm{H}_{2}\left(10 \% \mathrm{H}_{2} \mathrm{~S}\right)$ for 2 hours at $275^{\circ}$ and a second catalyst at $400^{\circ} \mathrm{C}$. The reactions of these catalysts with bibenzyl gave very poor conversions (Table 2). The lack of hydrocracking activity may be attributed to the absence of strong acid sites. XRD analysis of these catalysts showed the formation of pyrrhotite at both of these two sulfidation temperatures. Cugini and coworkers have reported that lower sulfidation temperature $\left(275^{\circ} \mathrm{C}\right)$ gave fine particles of pyrrhotite when coal is the support. The XRD data of the clay-supported hydroxyiron catalysts were unable to differentiate the particle size of the pyrrhotite formed under the conditions employed. Thus, catalysts prepared by the Cugini method may be effective in activating hydrogen for addition to polynuclear aromatics, but they are worthless for catalysis of hydrocracking reactions.

\subsubsection{Catalytic Hydrotreating of Pyrene}

Catalytic hydrotreating of pyrene was investigated to determine the activity of the sulfided iron-pillared clay for hydrogenation and hydrocracking of polynuclear aromatic systems common to most coals. These results were compared with the activity of sulfided commercial Ni-Moly catalyst. The reaction conditions, conversion data, and product distribution are given in Table 3 . 
TABLE 2

HYDROTREATING OF BIBENZYL WITH FEOOH CATALYSTS

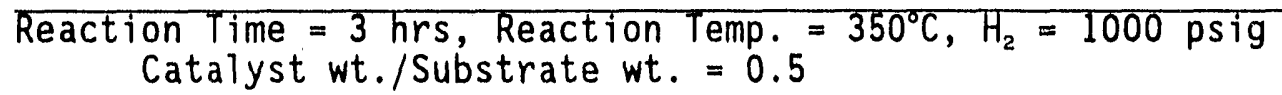

\begin{tabular}{cccc}
\hline $\begin{array}{c}\text { Catalyst } \\
(\mathrm{g})\end{array}$ & $\begin{array}{l}\text { Substrate } \\
(\mathrm{mmol})\end{array}$ & $\begin{array}{c}\text { Conversion } \\
(\%)\end{array}$ & Major Products \\
$(\mathrm{mmol})$
\end{tabular}

SMFeOOHa

Pre-sulfd

SMFeOOH

Pre-SuTfd.
2.75

2.84
8

7
Benzene $(0.14)$

Toluene $(0.02)$

Ethylbenzene (0.02)

Benzene $(0.11)$

Toluene $(0.02)$

Ethylbenzene $(0.02)$

$a=$ Pre-sulfided at $275^{\circ} \mathrm{C}$

$b=$ Presulfided at $400^{\circ} \mathrm{C}$

TABLE 3

Reactions of Pyrene

Reaction Temp. $=350^{\circ} \mathrm{C}$, Reaction Time $=3$ hours, $\mathrm{H}_{2}=1000$ ps $i$

Catalyst wt/Substrate $w t=0.5$

\begin{tabular}{|c|c|c|c|}
\hline Catalyst & $\begin{array}{l}\text { Substr. } \\
\text { (mmol) }\end{array}$ & $\begin{array}{l}\text { Conv. Major } \\
(\%)\end{array}$ & $\begin{array}{l}\text { Products } \\
\text { (mmol) }\end{array}$ \\
\hline
\end{tabular}

FEIPC $2.46 \quad 88$ Hexadecahydropyrene (0.05) (3 isomers)

(Sulfided)

$1,2,3,3 a, 4,5,9,10_{a}, 10_{b}$-Dec ahydropyrene $(0.15)$

$c-1,2,3,3_{a}, 4,5,5_{a}, 6,7,8$-Decahydropyrene $(0.13)$

$t-1,2,3,3 a, 4,5,5 a, 6,7,8$-Decahydropyrene $(0.17)$

$1,2,3,3,4,5$-Hexahydropyrene $(0.30)$

$1,2,3,6,7,8$-Hexahydropyrene $(0.46)$

$4,5,9,10$-Tetrahydropyrene $(0.08)$

4,5-Dihydropyrene $(0.25)$

HDN $-30 \quad 2.47$

$\mathrm{Ni}-\mathrm{Moly}$

69 Hexadecahydropyrene (0.03) (3 isomers)

(Sulfided)

$1,2,3,3,4,5,9,10_{a}, 10_{b}$-Decahydropyrene $(0.01)$

$c-1,2,3,3 a, 4,5,5,6,7,8$-Decahydropyrene $(0.05)$

$t-1,2,3,3_{a}, 4,5,5 a, 6,7,8$-Decahydropyrene $(0.06)$

$1,2,3,3 a, 4,5$-Hexahydropyrene $(0.21)$

$1,2,3,6,7,8$-Hexahydropyrene $(0.45)$

$4,5,9,10$-Tetrahydropyrene $(0.24))$

4,5-Dihydropyrene $(0.64)$ 
The reaction of pyrene with the iron-pillared montmorillonite gave a high conversion $(88 \%)$ of pyrene into products. The majority of the products were di-, hexa-, and decahydropyrenes. Since we did not calibrate for these isomers, data are derived from FID assuming the response factors of pyrene and hydropyrenes to be the same. Small amounts of hexdecahydro- and tetrahydropyrenes were also formed. Small amounts of other components were formed by hydrocracking and rearrangement reactions. The weight of the recovered catalyst was essentially the same as the initial catalyst, indicating no coking or retrogressive reaction had occurred with these catalysts. Hydrocracking to 1-, 2-, and 3-ring compounds was minimal under these conditions. The reaction of pyrene with commercial $\operatorname{Trilobe-HDN}(\mathrm{Ni}-\mathrm{Moly})$ catalyst gave a lower conversion $(69 \%)$. Major products were di-, tetra-, and hexahydropyrenes. Compared with the iron-pillared clay catalyst, the formation of decahydropyrene was significantly small. These data indicate that the hydrogenation activity of iron-pillared clay catalyst is better than the commercial nickel moly catalyst. Hydrogenation activity is also better than the commercial cobalt moly (AMOCAT) catalyst (7). Further work is in progress to develop catalysts and conditions suitable for hydrogen transfer as well hrdrocracking of polynuclear aromatics.

\subsection{REFERENCES}

1. Ryland, L.B.; Tamale, M.W.; Wilson, J.N. Catalysis, P.H. Emmett, Ed. Reinhold, New York, 1960, Vol 7, Chap. 1.

2. 01 son, E.S. Quarterly Technical Report for the Period Feb. 8, 1991, through May 8, 1991, DE-AC22-91PC90048.

3. Yamanaka, S.; Doi, T.; Sako, S.; Hattori, M. Mat. Res. Bull. 1984, 19, 161-168.

4. Cugini, A.V.; Utz, B.R.; Krastman, D.; Hickey, R.F.; Balsone, V. Preprints, ACS Div. of Fuel Chem. 1991, 36 (1), 91-102.

5. Oadıs, I.M. Clays and Clay Minerals 1984, 32, 49-57.

5. Lee, W.Y.; Raythatha, R.H; Tatarchuk, B.J. J. Catal. 1989, 115, 159179 .

7. 01 son, E.S. Quarterlv Progress Report for project DE-FC21-86MC10637, in preparation. 

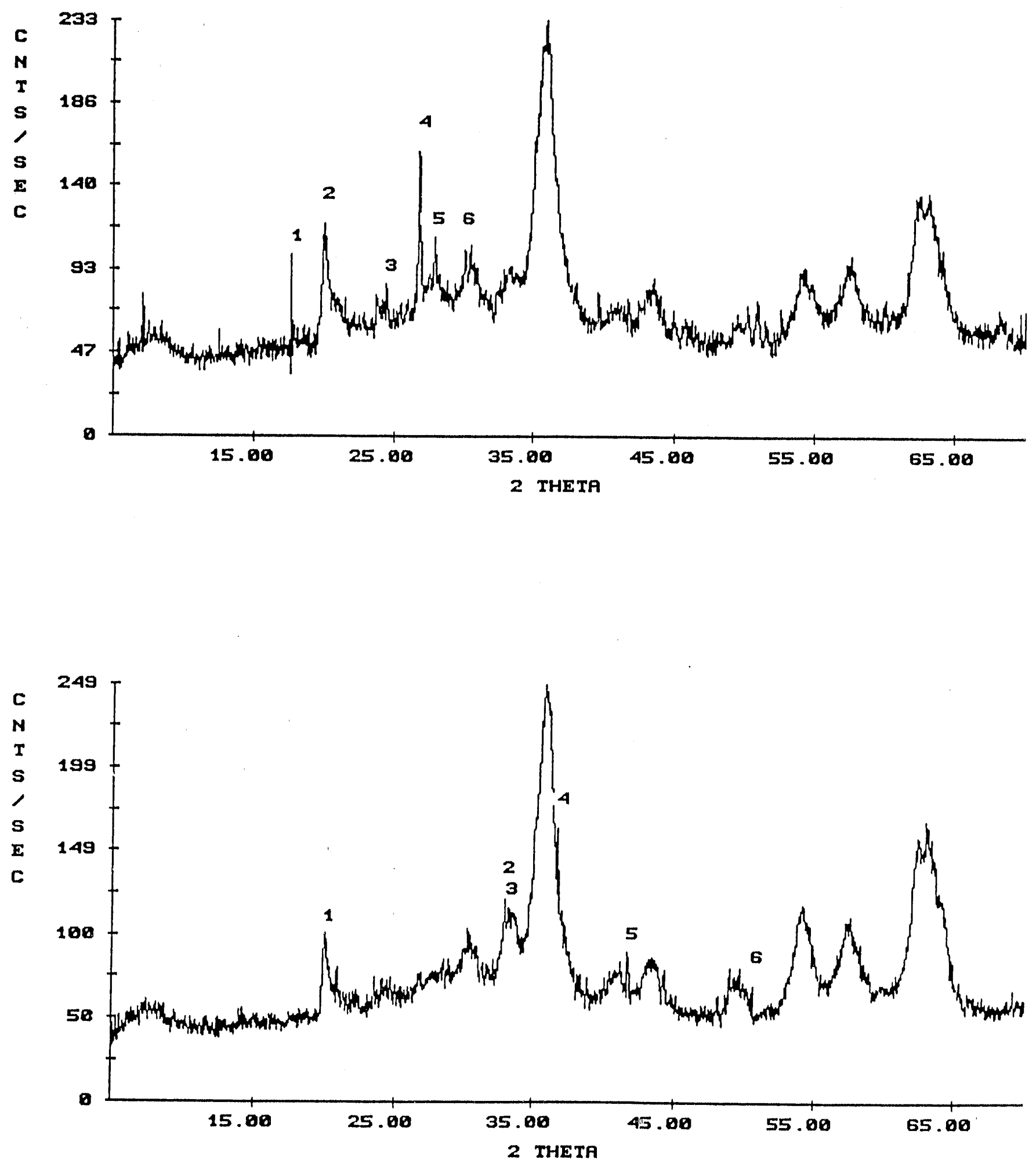

Figure 1. 2 Theta plots ior iron-pillared montmorillonites

A. LEIPC

B. FEIPC 


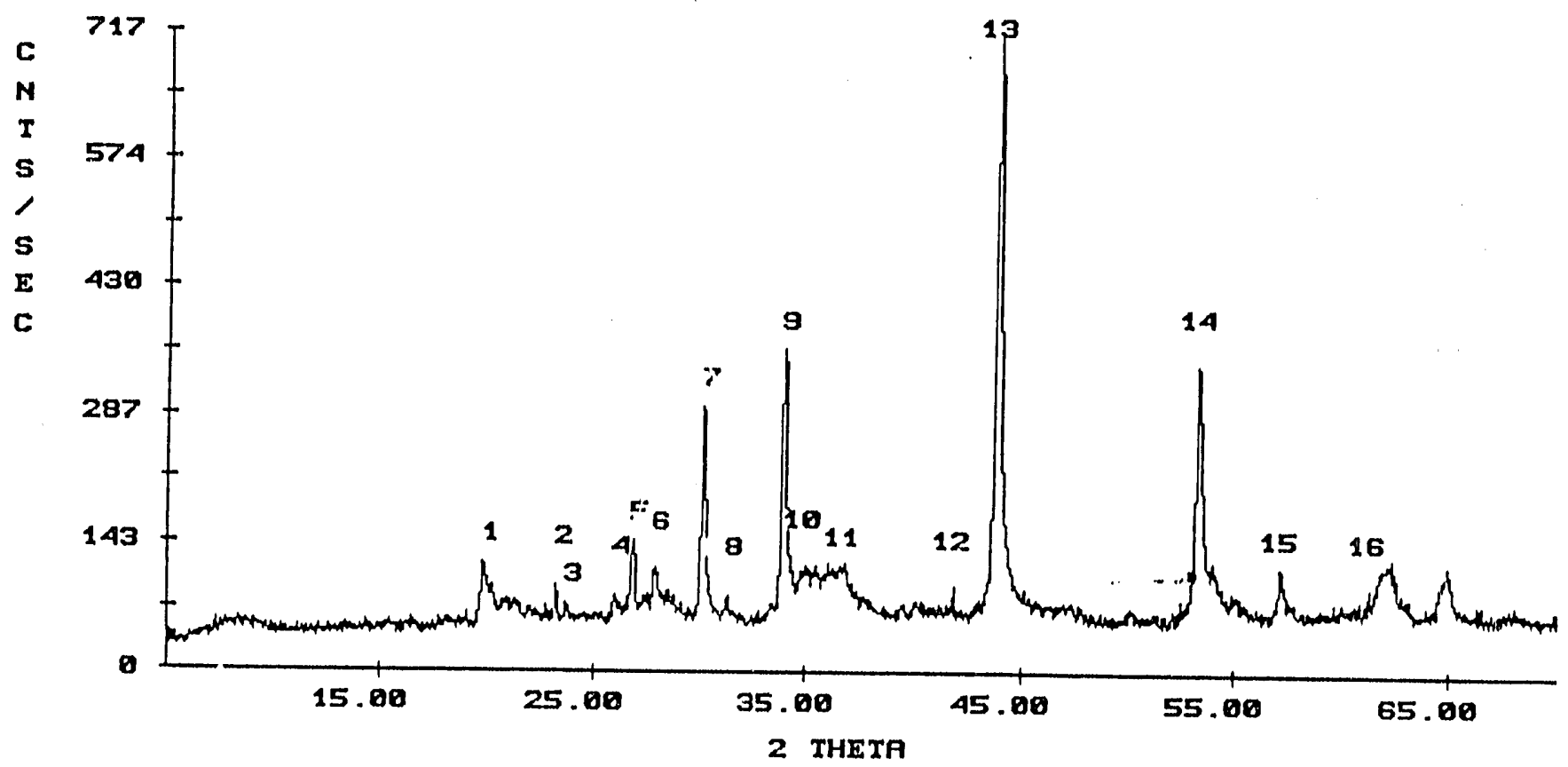

Figure 2. 2 Theta plot for sulfided iron-pillared montmorillonite (FEIPC) 


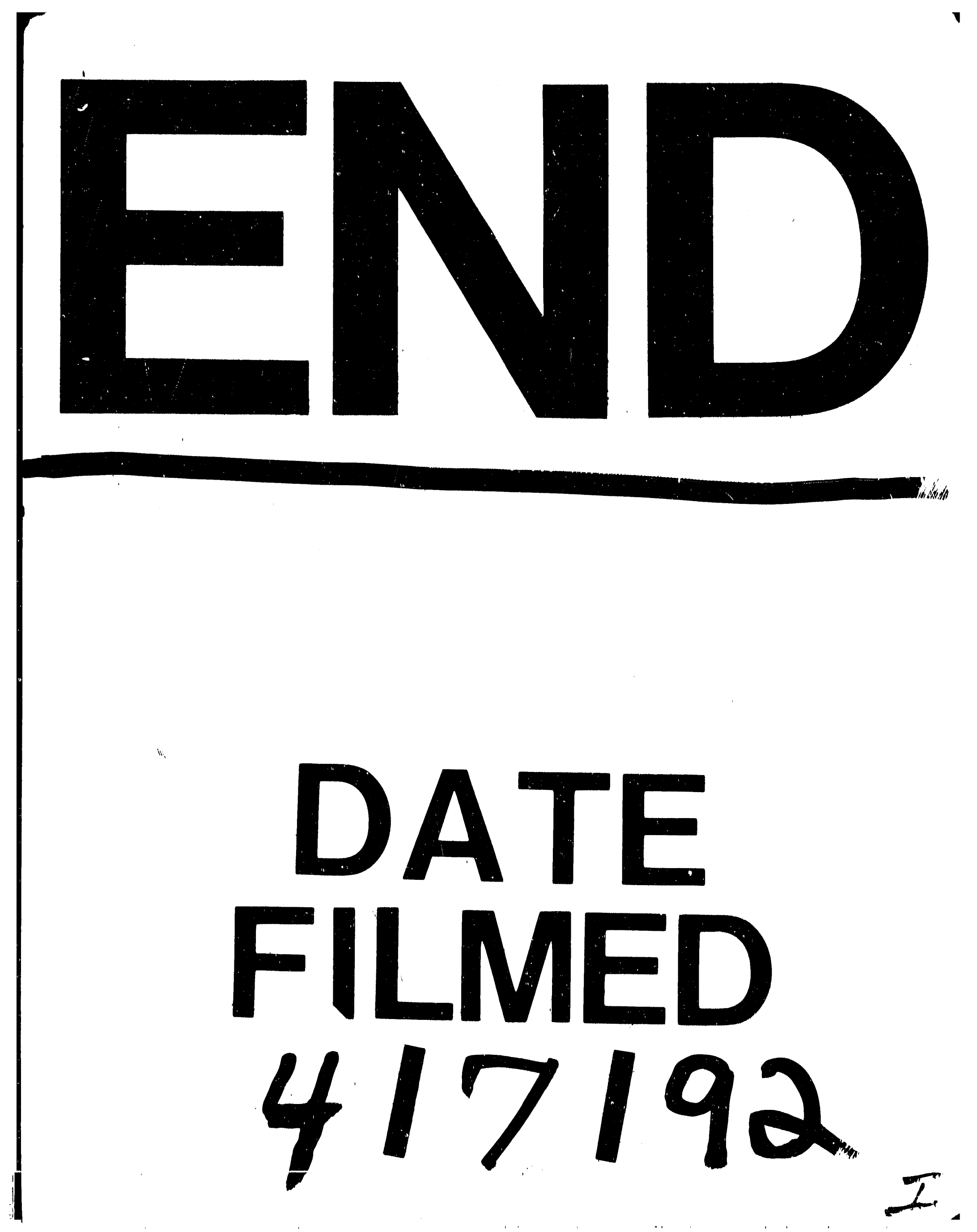


